\title{
Influence of Lysophosphatidylcholine on the C-Apolipoprotein Content of Rat and Human Triglyceride-Rich Lipoproteins during Triglyceride Hydrolysis
}

\author{
Eberhard E. T. Windler, Serena Preyer, and Heiner Greten \\ Medizinische Kernklinik und Poliklinik, Universitäts-Krankenhaus Eppendorf, D-2000 Hamburg 20, West Germany
}

\begin{abstract}
Remnants produced from rat chylomicrons in hepatectomized rats or from human chylomicrons by incubation in postheparin plasma contained much less $\mathbf{C}$-apolipoproteins, but more lysophosphatidylcholine than the parent chylomicrons. A phospholipid-triglyceride emulsion absorbed C-apolipoproteins during incubation in serum, yet not in postheparin plasma, which led to lipid-hydrolysis and increase in lysophosphatidylcholine. The fraction $d=1.006-1.019 \mathrm{~g} / \mathrm{ml}$ of human serum comprised more lysophosphatidylcholine and less $\mathrm{C}$-apolipoproteins than the fraction $d<1.006 \mathrm{~g} / \mathrm{ml}$. Injection of heparin induced hydrolysis with an increase in lysophosphatidylcholine and loss of C-apolipoproteins in both fractions. These inverse changes of lysophosphatidylcholine and C-apolipoproteins during lipid-hydrolysis suggest a causal relationship, which is strongly supported by the induction of loss of $\mathrm{C}$-apolipoproteins from rat chylomicrons and human triglyceride-rich lipoproteins by addition of lysophosphatidylcholine in vitro. Apolipoprotein C-II was more affected than C-III. These results may elucidate a mechanism for the regulation of the termination of the triglyceride hydrolysis and the final hepatic uptake of remnants.
\end{abstract}

\section{Introduction}

Very low density lipoproteins, secreted by the liver, and chylomicrons, secreted by the intestine, acquire most of their C-apoproteins (apolipoproteins) ${ }^{1}$ from high density lipoproteins after they have entered the extracellular space $(1,2)$. In addition lymph chylomicrons absorb apoprotein $\mathrm{E}$ and lose their A-apoproteins. In previous work it was shown that the acquisition of C-apoproteins prevents the premature uptake of the lipoproteins by the liver during the intravascular lipid hydrolysis $(1,3)$.

Lipid hydrolysis occurs by interaction with lipoprotein lipase at the endothelial surface of the capillaries in extrahepatic tissues resulting in the formation of remnant particles (4-6). Lipoprotein lipase catalyzes the hydrolysis of triglycerides (4) as well as the hydrolysis of phosphatidylethanolamine and phosphatidylcholine in triglyceride-rich lipoproteins and phospholipid-triglyceride

Presented in part at the 41 st Meeting of the European Atherosclerosis Group in Stockholm and at the Cologne Atherosclerosis Conference, No. 2, Lipids.

Address reprint requests to Dr. Windler.

Received for publication 8 January 1985 and in revised form 14 March 1986.

1. Abbreviations used in this paper: apoproteins, apolipoproteins.

J. Clin. Invest.

(c) The American Society for Clinical Investigation, Inc.

0021-9738/86/09/0658/08 $\$ 1.00$

Volume 78, September 1986, 658-665 emulsions (7-9). Both reactions are effectively enhanced by apoprotein $\mathrm{C}$-II, which activates the enzyme $(7,10,11)$. In vitro a second lipase, termed hepatic triglyceride lipase, independent of the activation by apoprotein C-II, also hydrolyzes triglycerides and phospholipids. Though its physiological role is controversial, it may also contribute to the intravascular metabolism of very low density lipoproteins $(12,13)$.

At the same time as the triglycerides are removed, the Capoproteins leave the surface of the partially degraded triglyceride-rich lipoproteins and are returned to high density lipoproteins $(6,14)$. Recent investigations indicate that there is a differential decrease in affinity for the $\mathrm{C}$-apoproteins during formation of remnants in the rat, as remnants of very low density lipoproteins and chylomicrons bound predominantly the apoproteins C-III- 0 and C-III-3 upon incubation with unfractionated C-apoproteins (15). With the reduction of apoprotein C-II the triglyceride hydrolysis ceases (4). Previous work provides evidence that the removal of apoprotein C-II and the apoproteins C-III-0 and C-III-3 allows recognition of the apoproteins B-100 and especially $E$ of the remnant particles by hepatic cell surface receptors, which leads to subsequent internalization of the lipoproteins $(1,3,16)$.

In the present investigation we have conducted a series of experiments designed to determine factors responsible for the loss of C-apoproteins during triglyceride hydrolysis of chylomicrons. Studies in vivo and in vitro in rat and man indicate that the relative enrichment of remnants in lysophosphatidylcholine that accompanies hydrolysis of triglycerides is important for the regulation of the reduction in the apoproteins $\mathrm{C}$-II and C-III.

\section{Methods}

Animals. Male Sprague-Dawley rats (Zentrale Versuchstieranstalt, Hanover, West Germany), weighing 300-350 g, were fed normal laboratory chow and tap water.

Preparation of rat small chylomicrons and remnants. Under light ether anesthesia a polyvinylchloride tube, external diameter $1 \mathrm{~mm}$, was inserted into the mesenteric lymph duct and a transcutaneous feeding tube was inserted into the duodenum. The abdominal cavity was closed with wound clips and the rats were kept in a restraining cage. Lymph was collected on ice during intraduodenal infusion of $10 \%$ glucose in $0.9 \% \mathrm{NaCl}(3.75 \mathrm{ml} / \mathrm{h})$ for up to $72 \mathrm{~h}$. The chemical composition of chylomicrons proved to be unchanged throughout this period. EDTA was added at a final concentration of $0.01 \%, \mathrm{pH} 7.4$. Small chylomicrons were isolated by ultracentrifugation (Beckman Instruments, Munich, West Germany) of lymph at $d=1.006 \mathrm{~g} / \mathrm{ml}$ for $2.5 \times 10^{7} \mathrm{gav}$ min at $4^{\circ} \mathrm{C}$ and purified by recentrifugation under the same conditions (17).

For functional evisceration the hepatic artery, the mesenteric arteries, and the portal vein of overnight fasted rats were ligated under light ether anesthesia. The liver was freed of all attached ligaments and the abdominal cavity was closed by means of wound clips. For preparation of remnants, small chylomicrons (10 mg of triglycerides per rat) were injected into the femoral vein. $30 \mathrm{~min}$ later the rats were bled by aortic puncture under ether anesthesia. Remnants were isolated by ultracentrifugation 
of the serum, made up to $d=1.019 \mathrm{~g} / \mathrm{ml}$ by $\mathrm{D}_{2} \mathrm{O}$ for $10^{8} \mathrm{gav}$ min at $4^{\circ} \mathrm{C}$, and were purified by a second centrifugation under the same conditions.

Preparation and analysis of apoproteins. For preparation of apoproteins, the very low density fraction of $d<1.006 \mathrm{~g} / \mathrm{ml}$ was prepared from rat serum by two consecutive centrifugations for $10^{8} \mathrm{gav}$ min at $4^{\circ} \mathrm{C}$. The very low density lipoproteins were delipidated with ether/ethanol (1:3, $\mathrm{vol} / \mathrm{vol}$ ) and ether (18). Proteins soluble in $6 \mathrm{M}$ urea and $0.015 \mathrm{M}$ Tris$\mathrm{HCl}, \mathrm{pH} 8.2$ were separated by gel permeation chromatography (Sephadex G-150, Pharmacia, Freiburg, West Germany) in the same buffer at $4^{\circ} \mathrm{C}$ (19). Fractions containing C-apoproteins or apoprotein $\mathrm{E}$ were pooled, concentrated by vacuum dialysis, dialyzed against several changes of $0.015 \mathrm{M}$ Tris- $\mathrm{HCl}, \mathrm{pH} 8.2$, and stored at $-20^{\circ} \mathrm{C}$. Purity of isolated apoproteins was determined by isoelectric focusing ( $\mathrm{pH} 3.5-7.0)$ in polyacrylamide gels (7.5\%) (20). Gels were stained in $4 \% \mathrm{H}_{3} \mathrm{PO}_{4}$ at $60^{\circ} \mathrm{C}$ with $2 \%$ Light Green SF yellowish for scanning and then with $2 \%$ Coomassie Brilliant Blue for better contrasts in photographs (Serva, Heidelberg, West Germany). Apoproteins of lipoproteins and of a lipid emulsion were identified by comparison of their pattern in isoelectric focusing gels in the presence of 2-mercaptoethanol with the previously characterized bands of triglyceride-rich lipoproteins and isolated apoproteins $(3,15)$. Proportions of apoproteins were estimated by densitometric scanning (electrophoresis densitometer, Saitron 805, Florence, Italy) of the bands stained with Light Green and determination of the areas below the peaks. When $50-350 \mu \mathrm{g}$ of total apoprotein of very low density lipoproteins from rat or humans were applied to gels, the absorption of the stained bands of the individual C-apoproteins showed a linear and parallel increase as in (21). For rat lymph chylomicrons the increase of absorption was linear up to $200 \mu \mathrm{g}$ of total apoprotein per gel, and standard deviations with this amount of applied protein were 8.6, 8.7, and 7.9\% for the apoproteins C-II, C-III-0, and C-III-3, respectively, in four preparations.

Experimental modifications of lipoproteins and a lipid emulsion. Sphingomyelin (bovine brain, $98 \%$ pure, Serva), $N$-oleyl-sphingomyelin (22), and lysophosphatidylcholine (egg yolk, 98\% pure, Serva) dissolved in chloroform appeared as pure fractions on thin-layer chromatography. Rat chylomicrons were isolated from mesenteric lymph as described above and human chylomicrons were prepared by centrifugation of serum from a normolipidemic subject $4 \mathrm{~h}$ after a meal of $500 \mathrm{ml}$ of cream $(30 \%$ fat) at $d=1.006 \mathrm{~g} / \mathrm{ml}$ for $8 \times 10^{7} \mathrm{~g}_{\mathrm{av}}$ min at $4^{\circ} \mathrm{C}$. The top fraction was purified by a second ultracentrifugation under the same conditions. Phospholipids were dried on the bottom of centrifuge tubes (cellulose nitrate, $2 \mathrm{ml}$, Beckman Instruments) under a stream of nitrogen and washed with diethylether. Chylomicrons in a small volume of $0.9 \% \mathrm{NaCl}$, $0.01 \%$ EDTA, $\mathrm{pH} 7.4$, were added and incubated at $37^{\circ} \mathrm{C}$ for $1 \mathrm{~h}$. After raising the density to $d=1.019 \mathrm{~g} / \mathrm{ml}$ by addition of $\mathrm{D}_{2} \mathrm{O}$, the mixture was overlayered with $0.9 \% \mathrm{NaCl}$ and the chylomicrons were reisolated by flotation for $6.3 \times 10^{5} \mathrm{gav}_{\mathrm{av}} \mathrm{min}$ at $4^{\circ} \mathrm{C}$. Aggregation of lipoproteins was excluded by measuring the optical density at $550 \mathrm{~nm}$ (3). Chylomicrons enriched in lysophosphatidylcholine had the same optical density per milligram of triglycerides as the untreated chylomicrons. In some experiments chylomicrons, remnants, and chylomicrons that had been incubated with lysophosphatidylcholine were incubated with isolated unfractionated $\mathrm{C}$-apoproteins for $1 \mathrm{~h}$ at room temperature and were reisolated by flotation through a layer of saline as described above with the exception of remnants, which were centrifuged at a final density of $d=1.019 \mathrm{~g} / \mathrm{ml}$.

Incubation of human chylomicrons and a lipid emulsion in serum and postheparin plasma. Serum that was free of very low density lipoproteins was prepared from serum of rats or a normolipemic subject with normal postheparin-lipoprotein-lipase activity by centrifugation for $10^{8} \mathrm{gav}_{\mathrm{av}} \mathrm{min}$ or $8 \times 10^{7} \mathrm{gav}_{\mathrm{av}} \mathrm{min}$, respectively, at $4^{\circ} \mathrm{C}$, after raising the density to $1.019 \mathrm{~g} / \mathrm{ml}$ by addition of $\mathrm{D}_{2} \mathrm{O}$. The top fraction was discarded and replaced with $0.9 \% \mathrm{NaCl}$. Postheparin plasma free of very low density lipoproteins was prepared as described above, but 10 min after intravenous injection of $60 \mathrm{IU}$ of heparin (Thrombophob, Nordmark, Hamburg, West Germany) per kg body wt. Human chylomicrons were prepared from the chylothorax of a patient with metastasized breast cancer by ultracentrifugation for $5.7 \times 10^{5} \mathrm{gav}_{\mathrm{av}} \mathrm{min}$ at $4^{\circ} \mathrm{C}$. After raising the density to $1.019 \mathrm{~g} / \mathrm{ml}$ with $\mathrm{D}_{2} \mathrm{O}$, the top fraction was overlayered with
$0.9 \% \mathrm{NaCl}$ and recentrifuged under the same conditions. $1 \mathrm{mg}$ of triglycerides of these chylomicrons or of a lipid emulsion (Intralipid, 10\%, KabiVitrum, Stockholm, Sweden) was incubated with serum and postheparin plasma free of very low density lipoproteins from human or rat, respectively, at $37^{\circ} \mathrm{C}$. At the indicated times samples were taken for determination of free fatty acids and the remainder was cooled in ice water, overlayered with $0.9 \% \mathrm{NaCl}$, and centrifuged for $8 \times 10^{7} \mathrm{~g}_{\mathrm{av}} \mathrm{min}$ in the case of chylomicrons, and $6.3 \times 10^{5} \mathrm{gav}_{\mathrm{av}}$ min for the lipid emulsion at $4^{\circ} \mathrm{C}$. The top fractions were recovered for analysis.

Analysis of human triglyceride-rich lipoproteins before and after heparin injection. Blood was taken from three normolipemic subjects in the fasting state and $4 \mathrm{~h}$ after a meal of $500 \mathrm{ml}$ or in one case $1,000 \mathrm{ml}$ of cream (30\% fat) and $10 \mathrm{~min}$ after intravenous injection of $60 \mathrm{IU}$ heparin/ $\mathrm{kg}$ body wt, which was administered just after the 4-h sample had been taken. The blood was immediately chilled in ice water and the serum or plasma centrifuged at $d=1.006 \mathrm{~g} / \mathrm{ml}$ for $8 \times 10^{7} \mathrm{~g}_{\mathrm{av}} \mathrm{min}$ at $4^{\circ} \mathrm{C}$. The bottom fraction was recentrifuged after raising the density to $1.019 \mathrm{~g}$ / $\mathrm{ml}$ with $\mathrm{D}_{2} \mathrm{O}$ under the above conditions. The top fractions of both centrifugations were purified by centrifugation under the same conditions and recovered for analysis.

Analyses. Determinations of protein and lipids were performed by standard procedures (23-27). Phospholipids were separated by unidimensional thin-layer chromatography on boric acid-impregnated plates (28) after extraction of lipids (29). Phospholipids were identified by comparison with purified standards (Serva) and overlap was excluded by two-dimensional thin-layer chromatography (30). All determinations represent the average of duplicate assays and duplicate chromatograms.

\section{Results}

Analysis of apoproteins and lipids in chylomicrons and remnants. Rat lymph chylomicrons showed the apoproteins A-I, A-IV, CII, C-III-0, and C-III-3 in isoelectric focusing gels, whereas remnants produced in functionally eviscerated rats showed mainly apoprotein E, only trace amounts of apoprotein C-III-0 and CIII-3, and virtually no apoprotein C-II (Fig. 1). Gel 5 in Fig. 1 contained only $25 \%$ as much $\mathrm{C}$-apoproteins as gel 1 . Incubation of chylomicrons and remnants with increasing concentrations of unfractionated C-apoproteins (C-II, C-III-0, C-III-3) resulted in an uptake of these apoproteins and was at the expense of the other apoproteins (Fig. 1). In chylomicrons the proportions of the individual C-components were not appreciably altered. Remnants still contained much less $\mathrm{C}$-apoproteins than chylomicrons and predominantly apoprotein C-III-0 and C-III-3. Apoprotein C-II represented $22.9 \%$ of total C-apoproteins in chylomicrons (gel 1 ) and an average of $17.8 \pm 3.2 \%$ in gels 3 to 5 , but only $5.2 \%$ in remnants (gel 5) and $8.4 \pm 0.3 \%$ in gels $6-8$.

Remnants from rat chylomicrons contained much less triglycerides, but were enriched in surface components and especially in cholesteryl esters as compared to the parent chylomicrons (Table I). Assuming that the amount of cholesteryl esters in the core of the particles remained constant, $85.8 \%$ of the triglycerides were hydrolyzed. The content of free fatty acids, measured in two preparations, dropped from a mean of $0.43 \%$ in chylomicrons to $0.28 \%$ of lipids in remnants and the ratio of free fatty acids over cholesteryl esters decreased from 0.12 in chylomicrons to 0.02 in remnants. The increase of total phospholipids in remnants was small, while the proportions of the individual phospholipids changed considerably (Table II). Phosphatidylethanolamine and phosphatidylcholine decreased, whereas sphingomyelin and lysophosphatidylcholine increased substantially.

Human chylomicrons from chylothorax absorbed C-apoproteins besides other unidentified proteins upon contact with 


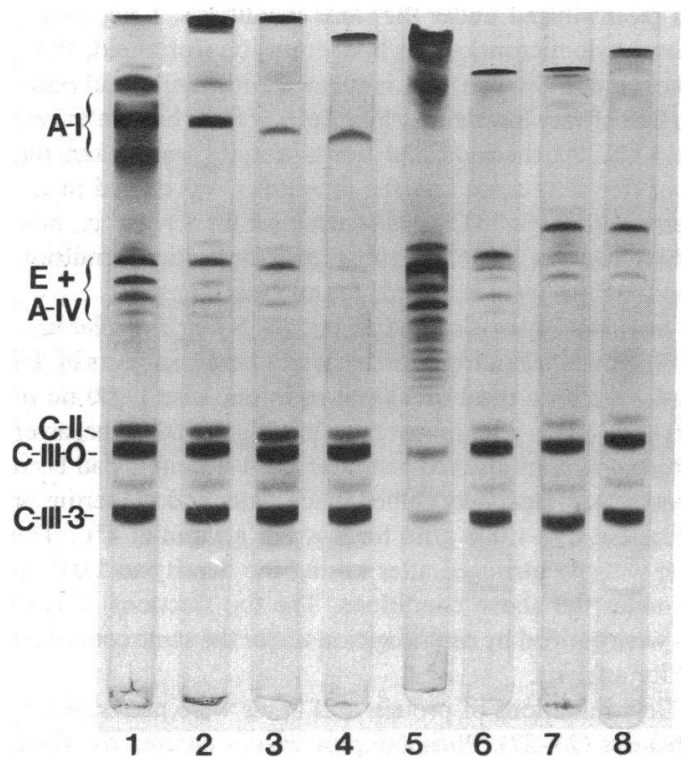

Figure 1. Isoelectric focusing polyacrylamide gel electrophoretograms of apoproteins of rat lymph small chylomicrons (1) and remnants (5) and of these lipoproteins after incubation with $0.25 \mathrm{mg}(2,6) 0.5 \mathrm{mg}$ $(3,7)$, or $1 \mathrm{mg}(4,8)$ unfractionated $\mathrm{C}$-apoproteins per $\mathrm{mg}$ apoprotein. After the incubation chylomicrons and remnants were reisolated by flotation at $d=1.006$ or $1.019 \mathrm{~g} / \mathrm{ml}$, respectively. Protein applied to each gel was derived from lipoproteins containing $200 \mathrm{mg}$ of total protein before incubation. One of two experiments is shown.

human serum free of very low density lipoproteins for 10 or $\mathbf{4 0}$ min. Incubation of $1 \mathrm{mg}$ of triglycerides of these chylomicrons in $1 \mathrm{ml}$ of postheparin plasma at $37^{\circ} \mathrm{C}$ resulted in release of free fatty acids (Fig. 2), yet in the fraction of $d<1.019 \mathrm{~g} / \mathrm{ml}$ there was no detectable change in the lipid composition $(81.5 \pm 0.9 \%$ triglycerides, $12.6 \pm 0.6 \%$ cholesterol, $5.9 \pm 0.4 \%$ phospholipids). The phospholipid composition, however, changed with time of incubation in postheparin plasma (Table III). A continuous rise in lysophosphatidylcholine was accompanied by a decrease in C-apoproteins of the fraction $d<1.019 \mathrm{~g} / \mathrm{ml}$ to $66.2,49.8,50.5$, and $39.1 \%(n=2)$ after contact with postheparin plasma for 10 , 20,30 , and $40 \mathrm{~min}$, respectively, as compared with chylomicrons incubated in serum.

During incubation of a phospholipid-triglyceride emulsion (96.7 $\pm 0.4 \%$ triglycerides, $2.6 \pm 0.2 \%$ phospholipids, $0.7 \pm 0.2 \%$ cholesterol) in rat postheparin plasma free of very low density lipoproteins, fatty acids were released (Fig. 3), but did not accumulate in the fraction $d<1.019 \mathrm{~g} / \mathrm{ml}(0.004 \%$ of lipids [wt/

Table I. Lipid Composition of Lymph Small Chylomicrons and Remnants

\begin{tabular}{lrr}
\hline Lipids & $\begin{array}{l}\text { Chylomicrons* } \\
n=3\end{array}$ & \multicolumn{1}{l}{$\begin{array}{l}\text { Remnants* } \\
n=5\end{array}$} \\
\hline Triglycerides & $76.7 \pm 1.5$ & $49.8 \pm 0.8$ \\
Free cholesterol & $1.7 \pm 0.6$ & $6.8 \pm 0.4$ \\
Cholesteryl esters & $4.8 \pm 0.3$ & $22.0 \pm 1.4$ \\
Phospholipids & $16.7 \pm 1.2$ & $21.6 \pm 1.8$
\end{tabular}

* Percent by weight \pm 1 SD.
Table II. Phospholipid Composition of Lymph Small Chylomicrons and Remnants

\begin{tabular}{lrr}
\hline Phospholipids & $\begin{array}{l}\text { Chylomicrons* } \\
n=7\end{array}$ & \multicolumn{1}{l}{$\begin{array}{l}\text { Remnants* } \\
n=4\end{array}$} \\
\hline Cardiolipin & $3.1 \pm 2.0$ & $1.5 \pm 0.7$ \\
Phosphatidylethanolamine & $11.6 \pm 0.8$ & $4.5 \pm 0.7$ \\
Phosphatidylcholine & $77.1 \pm 3.9$ & $62.5 \pm 1.3$ \\
Sphingomyelin & $3.0 \pm 1.2$ & $16.0 \pm 2.4$ \\
Lysophosphatidylcholine & $5.4 \pm 0.8$ & $17.3 \pm 1.3$ \\
\hline
\end{tabular}

* Percent phospholipid phosphorus \pm 1 SD.

wt] after $40 \mathrm{~min}$ ). While the lipid composition of the fraction $d$ $<1.019 \mathrm{~g} / \mathrm{ml}$ did not detectably change, the proportions of the individual phospholipids altered substantially with the most pronounced increase in lysophosphatidylcholine and a decrease in phosphatidylcholine (Table IV). The phospholipid-triglyceride-emulsion absorbed the $\mathrm{C}$-apoproteins and apoprotein $\mathrm{E}$ upon incubation in rat serum $(n=4)$. In contrast, with time of incubation in postheparin plasma the $\mathbf{C}$-apoprotein content decreased, while apoprotein $\mathrm{E}$ was retained. Densitometric scanning of two sets of isoelectric focusing gels showed that the content in total C-apoproteins dropped to 71 and $44 \%$ of the control after incubation for 5 and $10 \mathrm{~min}$ in postheparin plasma and was undetectable after $15 \mathrm{~min}$. The percentage of apoprotein CII decreased from $31 \%$ of total C-apoproteins in the control samples to 21 and $10 \%$ in the 5- and 10-min samples.

Enrichment of chylomicrons in sphingomyelin and lysophosphatidylcholine. Incubation of rat small chylomicrons with lysophosphatidylcholine resulted in a relative increase in this phospholipid with a concomitant decrease in phosphatidylcholine and phosphatidylethanolamine (Table V). The increase in lysophosphatidylcholine expressed as percentage of triglycerides from 1.8 to $6.2,9.9,16.5$, and $24.3 \%$, respectively, covered what was found in vivo in chylomicrons (1.2\%) and remnants $(7.5 \%)$ (Tables I and V). After incubation the content of chylomicrons in total phospholipids was not altered or only slightly increased by the highest concentrations of lysophosphatidylcholine. Increasing amounts of lysophosphatidylcholine were accompanied by a decrease of the protein content of chylomicrons (Table $\mathrm{V}$, Fig. 4). Isoelectric focusing gels revealed a loss of all soluble apoproteins characteristic of lymph chylomicrons (C-apoproteins and apoproteins A-I and A-IV). Scanning of the gels showed that total C-apoproteins dropped to $60,30,28$, and $15 \%$, respectively, of the control in gels 2 through 5 . Increasing concentrations of lysophosphatidylcholine diminished the ability of chylomicrons to bind $\mathrm{C}$-apoproteins upon incubation with these apoproteins (Fig. 4). As in remnants, primarily the apoproteins C-III-O and C-III-3 were bound, with apoprotein C-II dropping

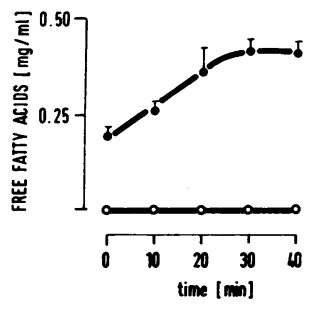

Figure 2. Accumulation of free fatty acids during incubation of human chylomicrons in serum (o) and postheparin plasma (๑) free of very low density lipoproteins. $1 \mathrm{mg}$ triglyceride was incubated in $1 \mathrm{ml}$ serum or plasma at $37^{\circ} \mathrm{C}$. Circles and bars represent mean and $1 \mathrm{SD}$ of three experiments. Fatty acids are given as milligrams of palmitic acid. 
Table III. Phospholipid Composition of Human Chylomicrons Incubated in Serum or Postheparin Plasma

\begin{tabular}{|c|c|c|c|c|c|c|}
\hline \multirow[b]{2}{*}{ Phospholipids } & \multicolumn{2}{|l|}{ Serum } & \multicolumn{4}{|c|}{ Postheparin plasma } \\
\hline & $10 \min$ & $40 \min$ & $10 \min$ & $20 \min$ & $30 \mathrm{~min}$ & $40 \mathrm{~min}$ \\
\hline \multicolumn{7}{|l|}{ Cardiolipin plus } \\
\hline Phosphatidylethanolamine & $11.3 \pm 1.1$ & $10.8 \pm 1.1$ & $9.7 \pm 4.5$ & $11.2 \pm 6.8$ & $11.3 \pm 8.4$ & $10.8 \pm 5.3$ \\
\hline Phosphatidylcholine & $54.8 \pm 9.5$ & $54.8 \pm 2.5$ & $53.8 \pm 1.8$ & $48.2 \pm 5.8$ & $46.0 \pm 7.6$ & $47.3 \pm 5.3$ \\
\hline Sphingomyelin & $25.5 \pm 2.8$ & $27.5 \pm 4.2$ & $26.7 \pm 3.5$ & $28.3 \pm 1.8$ & $30.3 \pm 9.0$ & $29.3 \pm 1.1$ \\
\hline Lysophosphatidylcholine & $8.5 \pm 2.1$ & $7.0 \pm 7.2$ & $10.3 \pm 1.5$ & $12.3 \pm 1.3$ & $12.5 \pm 2.3$ & $13.3 \pm 0.4$ \\
\hline
\end{tabular}

* Percent phospholipid phosphorus $\pm 1 \mathrm{SD}(n=3)$.

from 22 to $15,13,9$, and $8 \%$, respectively, of total C-apoproteins in gels 6-10. As with rat chylomicrons, the incubation of human postprandial triglyceride-rich lipoproteins with lysophosphatidylcholine $(0.01,0.02,0.03$, and $0.04 \mathrm{mg} / \mathrm{mg}$ triglycerides) led to a linear increase in this phospholipid from $4 \%$ (control) up to $39 \%$ of total phospholipids or 0.5 to $5.8 \%$ relative to triglycerides, comparable to 0.7 and $3.5 \%$ lysophosphatidylcholine per triglycerides in the fractions $1.006 \mathrm{~g} / \mathrm{ml}$ and $1.006-1.019 \mathrm{~g} / \mathrm{ml}$ postprandially in vivo (Tables V and VI). Enrichment in lysophosphatidylcholine was mainly at the expense of phosphatidylcholine. The lipid composition did not change $(82.4 \pm 1.1 \%$ triglycerides, $11.4 \pm 0.9 \%$ phospholipids, $6.2 \pm 0.4 \%$ cholesterol), but for a slight increment in phospholipids from $10.4 \%$ in the control to $12.2 \%$ with the highest concentration. The content in C-apoproteins decreased to $83,77,69$, and $44 \%$ of the control as measured in isoelectric focusing gels.

In control incubations of sphingomyelin or lysophosphatidylcholine with $0.9 \% \mathrm{NaCl}$, no or only trace amounts of the phospholipids could be detected by thin-layer chromatography of the fraction $d<1.006 \mathrm{~g} / \mathrm{ml}$. Incubation of rat small chylomicrons with sphingomyelin resulted in a comparatively small average increase in this phospholipid maximally from 1 to $6 \%$, probably due to a low affinity of sphingomyelin to chylomicrons. Prolongation of the time of incubation or raising the temperature above the liquid crystalline transition temperature to $47^{\circ} \mathrm{C}$ for sphingomyelin from bovine brain (31) or to $37^{\circ} \mathrm{C}$ for $N$-oleylsphingomyelin (7) did not appear to be more efficient modifications of the procedure. Under all conditions sphingomyelin did not induce a detectable change of the apoprotein pattern.

Analysis of human triglyceride-rich lipoproteins. Serum lipids in the fasted state, after a fatty meal, and after heparin injection are shown in Fig. 5. The drop of triglycerides after injection of heparin indicates hydrolysis and the decrease of cholesterol suggests removal of remnants from the plasma. The chemical compositions and the phospholipid compositions of the fraction $d$

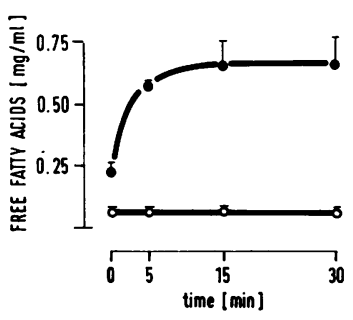

Figure 3. Accumulation of free fatty acids during incubation of a phospholipid-triglyceride emulsion in rat serum $(0)$ or postheparin plasma (๑) free of very low density lipoproteins. 1 $\mathrm{mg}$ triglyceride was incubated in $1 \mathrm{ml}$ serum or plasma at $37^{\circ} \mathrm{C}$. Circles and bars represent mean and $1 \mathrm{SD}$ of three experiments. Fatty acids are given as milligrams of palmitic acid.
$<1.006 \mathrm{~g} / \mathrm{ml}$ and the fraction $d=1.006-1.019 \mathrm{~g} / \mathrm{ml}$ representing remnants are given in Tables VI and VII. The remnant fraction contained less triglycerides but was enriched in surface components as compared with that of $d<1.006 \mathrm{~g} / \mathrm{ml}$. After heparin injection the two fractions became more alike, probably due to the accelerated triglyceride hydrolysis resulting in a shift of partially catabolized particles into the density fraction of remnants and at the same time removal of triglyceride-poor remnants from the plasma. Due to these sudden changes the two fractions are likely to contain different particles before and after injection of heparin, limiting the comparison of the composition of the fractions before and after treatment. In all cases free fatty acids comprised $<10^{-3} \%$ of lipids in each fraction. Sphingomyelin and lysophosphatidylcholine were invariably increased in the remnant fraction, except after heparin injection when lysophosphatidylcholine increased fourfold in the fraction $d<1.006 \mathrm{~g} / \mathrm{ml}$, so that the fractions of $d<1.006$ and $d=1.006-1.019 \mathrm{~g} / \mathrm{ml}$ obtained similar phospholipid compositions. Fig. 6 shows the isoelectric focusing gels of the apoproteins. Densitometric scans revealed that remnants in the fasted or postprandial state contained $25.8 \pm 16.5 \%(n=3)$ or $13.6 \pm 11.5 \%(n=3)$, respectively, of $\mathrm{C}$-apoproteins of the fraction $d<1.006 \mathrm{~g} / \mathrm{ml}$, when related to equal amounts of cholesterol. After heparin injection the Capoprotein content even dropped to $26.0 \pm 13.1 \%(n=5)$ and $18.0 \pm 26.4 \%(n=3)$ in the fractions $d<1.006 \mathrm{~g} / \mathrm{ml}$ and $d$ $=1.006-1.019 \mathrm{~g} / \mathrm{ml}$, respectively, as compared with the postprandial triglyceride-rich lipoproteins or their remnants before heparin injection.

Table IV. Phospholipid Composition of a Phospholipid-Triglyceride-Emulsion Incubated in Rat Serum or Postheparin Plasma

\begin{tabular}{|c|c|c|c|c|}
\hline \multirow[b]{2}{*}{ Phospholipids } & \multirow{2}{*}{$\frac{\text { Serum }}{30 \mathrm{~min}}$} & \multicolumn{3}{|c|}{ Postheparin plasma } \\
\hline & & $5 \min$ & $15 \mathrm{~min}$ & $30 \mathrm{~min}$ \\
\hline Cardiolipin & $4.3 \pm 1.0$ & $6.9 \pm 3.8$ & $10.3 \pm 3.0$ & $12.3 \pm 6.2$ \\
\hline $\begin{array}{l}\text { Phosphatidyl- } \\
\text { ethanolamine }\end{array}$ & $8.8 \pm 4.9$ & $7.6 \pm 2.9$ & $10.0 \pm 3.3$ & $12.9 \pm 4.7$ \\
\hline Phosphatidylcholine & $63.8 \pm 5.9$ & $45.1 \pm 6.8$ & $40.8 \pm 6.9$ & $35.6 \pm 7.3$ \\
\hline Sphingomyelin & $13.2 \pm 1.4$ & $11.4 \pm 3.9$ & $13.1 \pm 1.8$ & $13.2 \pm 2.3$ \\
\hline $\begin{array}{l}\text { Lysophosphatidyl- } \\
\text { choline }\end{array}$ & $11.0 \pm 2.3$ & $28.4 \pm 6.7$ & $26.3 \pm 3.5$ & $26.3 \pm 4.5$ \\
\hline
\end{tabular}

* Percent phospholipid phosphorus \pm 1 SD $(n=4)$. 
Table V. Chemical Composition and Phospholipid Composition of Rat Lymph Small Chylomicrons Incubated with Lysophosphatidylcholine

\begin{tabular}{|c|c|c|c|c|c|}
\hline & \multirow[b]{2}{*}{ Control } & \multicolumn{4}{|c|}{$\begin{array}{l}\text { Incubated with } \\
\text { lysophosphatidylcholine } \\
\text { (mg/mg triglycerides) }\end{array}$} \\
\hline & & 0.100 & 0.125 & 0.250 & 0.500 \\
\hline Protein* & 2.8 & 1.9 & 1.0 & 0.016 & 0.0 \\
\hline Phospholipids* & 17.5 & 17.9 & 19.9 & 23.6 & 27.4 \\
\hline Cholesterol $^{*}$ & 5.3 & 4.9 & 4.9 & 4.0 & 3.6 \\
\hline Triglycerides* & 74.4 & 75.4 & 74.1 & 72.2 & 69.0 \\
\hline \multicolumn{6}{|l|}{ Cardiolipin plusł } \\
\hline Phosphatidylethanolamineł & 15.2 & 8.8 & 10.9 & 9.9 & 6.1 \\
\hline Phosphatidylcholineł & 72.8 & 57.5 & 47.9 & 32.2 & 26.2 \\
\hline Sphingomyelinł & 4.8 & 3.4 & 4.3 & 3.9 & 3.1 \\
\hline Lysophosphatidylcholineł & 7.5 & 26.0 & 37.0 & 50.5 & 61.1 \\
\hline
\end{tabular}

* Percent by weight $(n=2)$.

$\ddagger$ Percent phospholipid phosphorus $(n=2)$.

\section{Discussion}

The mechanisms regulating the changes of the apoprotein composition of triglyceride-rich lipoproteins during their intravascular metabolism have not yet been elucidated. This investigation confirms the observation of a diminished $\mathrm{C}$-apoprotein content in remnants and a differential loss of affinity for apoprotein CII and the C-III-apoproteins during triglyceride hydrolysis of rat chylomicrons $(6,15)$. The results indicate that the relative increase in lysophosphatidylcholine during remnant formation induces a transfer of the C-apoproteins to high density lipoproteins. The observations obtained with remnants produced in hepatectomized rats and with human lipoproteins in vivo or hydrolyzed in vitro are in agreement with this concept. These results match those of experiments in vitro with lipoproteins modified with lysophosphatidylcholine to obtain a ratio of lysophosphatidylcholine per triglyceride found in remnants in vivo. The induction of a transfer of C-apoproteins by enrichment in lysophosphatidylcholine in the absence of other plasma constituents strongly supports the assumption of a causal relationship. The quantitative aspects of the dose-response relationship may be modulated in vivo by a number of factors such as particle size and composition, concentrations of apoproteins, or of high density lipoproteins. Because of absorption of lysophosphatidylcholine by high density lipoproteins it was not feasible to study their influence on the induced transfer of $\mathrm{C}$-apoproteins in vitro. As an acceptor for C-apoproteins high density lipoproteins might augment the effect of lysophosphatidylcholine, if at all, since their presence was not necessary. Neither triglyceride hydrolysis with reduction of particle size, though possibly contributive in vivo, nor increase in total phospholipids were necessary prerequisites for the alterations in the apoprotein pattern of chylomicrons. The experiments with the phospholipid-triglyceride-emulsion illustrate that the effect of lysophosphatidylcholine is independent of particle size and structure or changes in the cholesterol content. Accumulation of free fatty acids as a contributing factor has been excluded, as fatty acids were not retained on the surface of remnants. Though mono- and diglycerides have not been measured in this investigation, there is no evidence from previous studies that these glycerols accumulate during lipolysis as long as plasma components, especially high density lipoproteins, platelets, and albumin are present (1, 32-34).

Two mechanisms may contribute to the rise of lysophosphatidylcholine in chylomicrons during triglyceride hydrolysis. A major part of phospholipids leaves the chylomicrons during remnant formation; in our experiments with rat chylomicrons this was more than $70 \%$, calculated on the basis of a constant content in cholesteryl esters. During this depletion relatively more lysophosphatidylcholine may be retained on the particles

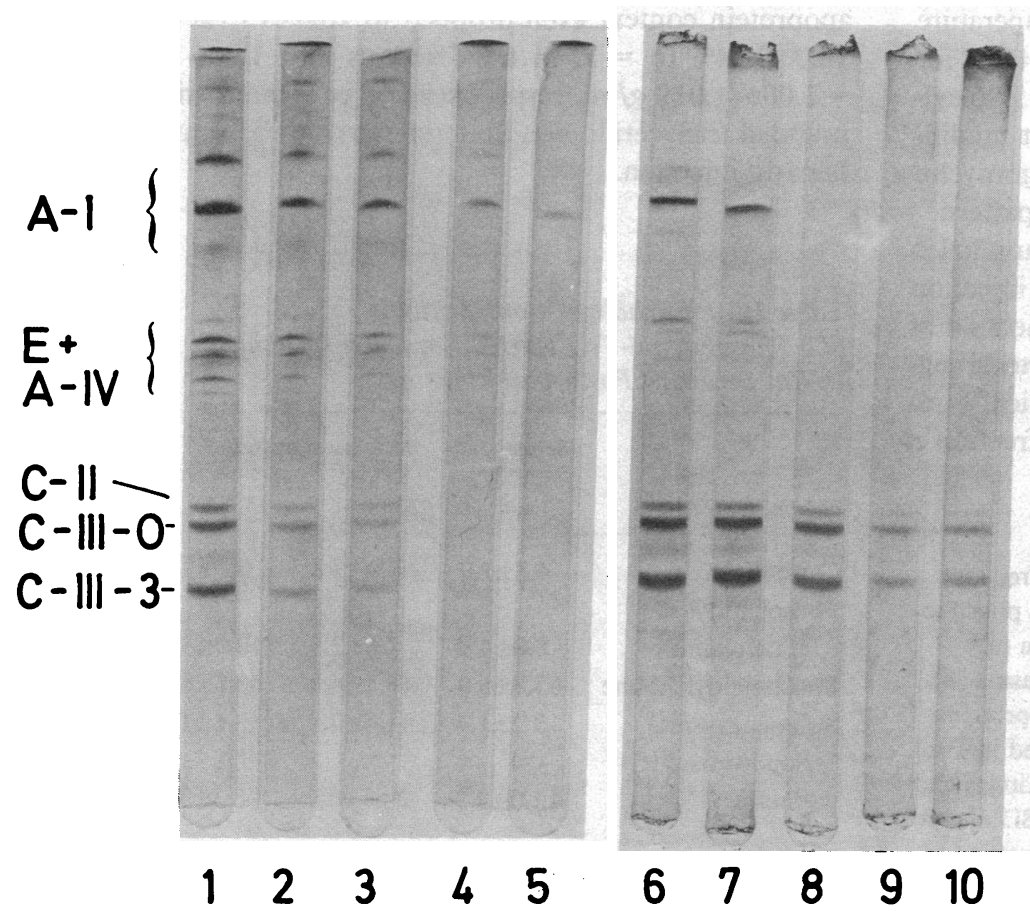

Figure 4. Isoelectric focusing polyacrylamide gel electrophoretograms of apoproteins of lymph small chylomicrons enriched in lysophosphatidylcholine (1-5) or in lysophosphatidylcholine and unfractionated $\mathrm{C}$-apoproteins (6-10). Chylomicrons were incubated without (1) or with $0.1 \mathrm{mg}$ (2), $0.125 \mathrm{mg}$ (3), $0.25 \mathrm{mg}$ (4), or $0.5 \mathrm{mg}$ (5) lysophosphatidylcholine per $1 \mathrm{mg}$ triglyceride for $1 \mathrm{~h}$ at $37^{\circ} \mathrm{C}$, and were reisolated by flotation at $d=1.006 \mathrm{~g} / \mathrm{ml}$. Gels 6-10 show samples $1-5$ after subsequent incubation with $0.5 \mathrm{mg} \mathrm{C}$-apoproteins per $1 \mathrm{mg}$ apoprotein of the control or the equivalent amount of lipoproteins of the other samples for $1 \mathrm{~h}$ at room temperature and reisolation by flotation at $d=1.006 \mathrm{~g} / \mathrm{ml}$. Protein applied to each gel was derived from lipoproteins containing $2.5 \mathrm{mg}$ triglycerides. Gels 1-5 represent one of five and gels 6-10 one of two experiments. 
Table VI. Chemical Composition of the Fractions $d<1.006 \mathrm{~g} / \mathrm{ml}$ and $d=1.006-1.019 \mathrm{~g} / \mathrm{ml}$ of Human Serum

\begin{tabular}{|c|c|c|c|c|c|c|}
\hline & \multicolumn{2}{|l|}{ Fasted } & \multicolumn{2}{|l|}{$4 \mathrm{~h}$ Postprandial } & \multicolumn{2}{|c|}{$10 \mathrm{~min}$ After heparin injection } \\
\hline & $\begin{array}{l}d<1.006 \\
g / m l \\
n=4\end{array}$ & $\begin{array}{l}d=1.006-1.019 \\
g / m l \\
n=3\end{array}$ & $\begin{array}{l}d<1.006 \\
g / m l \\
n=5\end{array}$ & $\begin{array}{l}d=1.006-1.019 \\
g / m l \\
n=4\end{array}$ & $\begin{array}{l}d<1.006 \\
g / m l \\
n=4\end{array}$ & $\begin{array}{l}d=1.006-1.019 \\
g / m l \\
n=3\end{array}$ \\
\hline Triglycerides & $56.8 \pm 4.6^{* *}$ & $40.5 \pm 4.0$ & $68.6 \pm 5.7^{* * * * *} \neq \ddagger$ & $41.1 \pm 1.5 \S \S$ & $61.8 \pm 5.6$ & $57.0 \pm 5.5$ \\
\hline Cholesterol & $10.1 \pm 0.9^{*}$ & $17.4 \pm 1.8$ & $7.5 \pm 1.1^{* * * * *} \ddagger$ & $17.5 \pm 0.6 \$ \$ \S$ & $11.3 \pm 2.6$ & $14.6 \pm 0.7$ \\
\hline Phospholipids & $17.6 \pm 0.3$ & $19.6 \pm 3.6$ & $14.5 \pm 2.6^{* * *}$ & $18.6 \pm 1.6$ & $15.1 \pm 3.1$ & $15.2 \pm 3.2$ \\
\hline Protein & $15.4 \pm 3.8$ & $23.0 \pm 7.9$ & $8.5 \pm 2.6^{* * *}$ & $22.8 \pm 2.6 \S$ & $11.9 \pm 3.1$ & $13.2 \pm 2.3$ \\
\hline
\end{tabular}

* $P<0.05,{ }^{* *} P<0.02,{ }^{* * *} P<0.01,{ }^{* * * *} P<0.002$ for differences between $d<1.006 \mathrm{~g} / \mathrm{ml}$ and $d=1.006-1.019 \mathrm{~g} / \mathrm{ml}$. $¥ P<0.01, \neq \ddagger P$ $<0.002$ for differences between $d<1.006 \mathrm{~g} / \mathrm{ml} 4 \mathrm{~h}$ postprandial and $10 \mathrm{~min}$ after heparin injection. $\S P<0.05, \S P<0.02, \S \S P<0.002$ for differences between $d=1.006-1.019 \mathrm{~g} / \mathrm{ml} 4 \mathrm{~h}$ postprandial and $10 \mathrm{~min}$ after heparin injection.

as compared with the other phospholipids. Secondly, lysophosphatidylcholine may be derived from phosphatidylcholine, which is reported to be hydrolyzed rather than transferred to high density lipoproteins (35). The lecithin/cholesterol acyltransferase has earlier been ruled out as a major factor contributing to the formation of lysophosphatidylcholine during chylomicron hydrolysis (35-37). Phospholipase $A_{1}$ activity has been attributed to lipoprotein lipase as well as hepatic triglyceride lipase $(8,38$, 39). These studies with purified enzymes agree with findings in vivo (36). The observation of a decrease in phosphatidylethanolamine and phosphatidylcholine but not sphingomyelin with an increase in lysophosphatidylcholine during remnant formation in vivo matches data indicating that intravascular phospholipase activity of lipoprotein lipase is restricted to phosphatidylcholine and phosphatidylethanolamine with no activity toward sphingomyelin $(4,9)$. Even if apoprotein C-II, the activator of lipoprotein lipase, is lost from chylomicrons during remnant formation, phospholipid hydrolysis may continue due to hepatic triglyceride lipase, which is independent of apoprotein C-II (8, $38,39)$. Lysophosphatidylcholine thus might increase further forcing remaining apoprotein C-III-0 and C-III-3 to leave the remnants. It should be considered though that very small amounts of apoprotein C-II are sufficient to maintain activation of lipoprotein lipase (40).

The mechanisms by which lysophosphatidylcholine influences the apoprotein pattern may be competition with the other surface components. In favor of this hypothesis is the finding of a high affinity of lysophosphatidylcholine for chylomicrons as compared with sphingomyelin during incubation with these phospholipids. Lysophosphatidylcholine is known to strongly interact with membranes containing protein $(41,42)$. The effect of lysophosphatidylcholine may be enhanced by its physico-

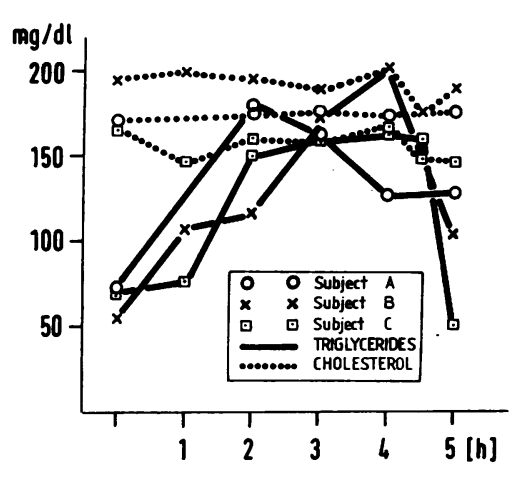

Figure 5. Serum lipids after ingestion of $500 \mathrm{ml}$ of cream ( $30 \%$ fat). After $4 \mathrm{~h}$ subjects $B$ and $C$ were injected with $60 \mathrm{IU}$ heparin per kg body wt i.v. chemical properties, as upon dispersion in water lysophosphatidylcholine does not form bilayers but only micelles, so that destabilization of the surface structure and interference with the binding of apoproteins and other phospholipids can be expected (43). This interaction may lead to dissociation of C-apoproteins from the particles after a certain concentration of lysophosphatidylcholine has been reached during remnant formation. The effect may be modulated by other surface components such as cholesterol $(42,43)$ and probably varies with each individual apoprotein, which might explain their differential behavior. Studies on the surface activities of the C-apoproteins could not show a difference for these apoproteins in a system in vitro (44). Still, the differential loss of apoprotein C-II and apoprotein CIII shown for the rat might be due to a difference in their affinity to the triglyceride-rich lipoproteins or their susceptibility to lysophosphatidylcholine. In man this difference was not as obvious, although in vivo remnants contained $25-30 \%$ less apoprotein

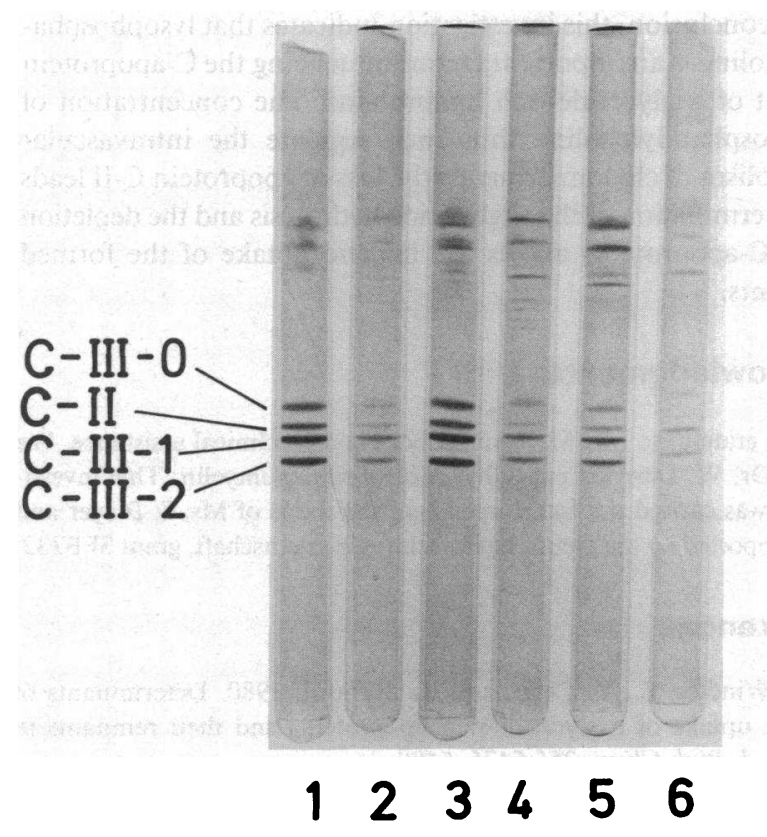

Figure 6. Isoelectric focusing polyacrylamide gel electrophoretograms of human apoproteins in the fractions $d<1.006 \mathrm{~g} / \mathrm{ml}(1,3,5)$ and $d$ $=1.006-1.019 \mathrm{~g} / \mathrm{ml}(2,4,6)$ in the fasted state $(1,2), 4 \mathrm{~h}$ after $500 \mathrm{ml}$ of cream $(3,4)$ and $10 \mathrm{~min}$ after subsequent administration of $60 \mathrm{IU}$ heparin per $\mathrm{kg}$ body wt i.v. $(5,6) .200 \mu \mathrm{g}$ protein were applied to each gel. One of five experiments is shown. 
Table VII. Phospholipid Composition of the Fractions $d<1.006 \mathrm{~g} / \mathrm{ml}$ and $d=1.006-1.019 \mathrm{~g} / \mathrm{ml}$ of Human Serum

\begin{tabular}{|c|c|c|c|c|c|c|}
\hline & \multirow{2}{*}{$\begin{array}{l}\text { Fasted } \\
d<1.006 \\
g / m l \\
n=4\end{array}$} & \multicolumn{3}{|c|}{$4 \mathrm{~h}$ Postprandial } & \multicolumn{2}{|c|}{$10 \mathrm{~min}$ After heparin injection } \\
\hline & & $\begin{array}{l}d=1.006-1.019 \\
g / m l \\
n=4\end{array}$ & $\begin{array}{l}d<1.006 \\
g / m l \\
n=5\end{array}$ & $\begin{array}{l}d=1.006-1.019 \\
g / m l \\
n=5\end{array}$ & $\begin{array}{l}d<1.006 \\
g / m l \\
n=4\end{array}$ & $\begin{array}{l}d=1.006-1.019 \\
g / m l \\
n=4\end{array}$ \\
\hline Cardiolipin & $3.2 \pm 1.3$ & $9.7 \pm 9.4$ & $2.2 \pm 1.1^{*}$ & $9.1 \pm 5.0$ & $4.8 \pm 2.7^{*}$ & $11.8 \pm 5.5$ \\
\hline Phosphatidylethanolamine & $7.7 \pm 3.2$ & $8.6 \pm 6.9$ & $7.0 \pm 2.5$ & $9.4 \pm 4.5$ & $6.4 \pm 3.6^{*}$ & $10.7 \pm 3.8$ \\
\hline Phosphatidylcholine & $75.7 \pm 11.5^{*}$ & $54.5 \pm 22.4$ & $77.5 \pm 8.4^{* * *, \ddagger}$ & $54.2 \pm 12.1$ & $59.6 \pm 9.6^{* *}$ & $47.4 \pm 9.3$ \\
\hline Sphingomyelin & $10.5 \pm 5.9^{* *}$ & $18.8 \pm 2.4$ & $10.3 \pm 4.7^{* *} \ddagger \ddagger \ddagger$ & $19.6 \pm 2.9$ & $17.4 \pm 2.0$ & $19.6 \pm 2.9$ \\
\hline Lysophosphatidylcholine & $3.1 \pm 1.9^{*}$ & $8.5 \pm 5.0$ & $3.1 \pm 1.4^{* *} \neq \ddagger$ & $7.8 \pm 1.5$ & $12.0 \pm 3.7$ & $10.8 \pm 2.3$ \\
\hline
\end{tabular}

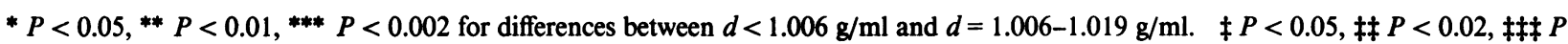
$<0.002$ for differences between $d<1.006 \mathrm{~g} / \mathrm{ml} 4 \mathrm{~h}$ postprandial and $d<1.006 \mathrm{~g} / \mathrm{ml} 10 \mathrm{~min}$ after heparin injection. Results of $d=1.006-1.019$ $\mathrm{g} / \mathrm{ml} 4 \mathrm{~h}$ postprandial and $10 \mathrm{~min}$ after heparin injection were not significantly different.

C-II per total C-apoprotein as compared with the parent lipoproteins, which again decreased after heparin injection. An influence of lysophosphatidylcholine on the apoproteins A-I and A-IV, though seen in vitro with lymph chylomicrons, is not likely to be important in vivo, as lymph chylomicrons lose these apoproteins immediately upon contact with serum without triglyceride hydrolysis (2). Apoprotein E should be slightly or not at all influenced by lysophosphatidylcholine, as remnants are known to be rich in this apoprotein. Apart from confirming this basic observation our experiments do not provide information on this apoprotein, but for the interesting finding that apoprotein $\mathrm{E}$, absorbed by the phospholipid-triglyceride emulsion, was retained during triglyceride hydrolysis despite increasing concentrations of lysophosphatidylcholine, supporting the above hypothesis. In view of these differences in behavior of the various apoproteins, further physicochemical studies are necessary for a better understanding of the mechanisms involved.

In conclusion, this investigation indicates that lysophosphatidylcholine is an important factor influencing the $\mathrm{C}$-apoprotein content of triglyceride-rich lipoproteins. The concentration of lysophosphatidylcholine thus may regulate the intravascular metabolism of chylomicrons, as the loss of apoprotein C-II leads to the termination of the triglyceride hydrolysis and the depletion of all C-apoproteins allows the hepatic uptake of the formed remnants.

\section{Acknowledgments}

We are grateful to Ms. M. Apel for her expert technical assistance. We thank Dr. W. Därr for providing $N$-oleyl-sphingomyelin. This investigation was carried out in the course of the thesis of Ms. S. Preyer and was supported by the Deutsche Forschungsgemeinschaft, grant SFB232.

\section{References}

1. Windler, E., Y. Chao, and R. J. Havel. 1980. Determinants of hepatic uptake of triglyceride-rich lipoproteins and their remnants in the rat. J. Biol. Chem. 255:5475-5480.

2. Imaizumi, K., M. Fainaru, and R. J. Havel. 1978. Composition of proteins of mesenteric lymph chylomicrons in the rat and alterations produced upon exposure of chylomicrons to blood serum and serum proteins. J. Lipid Res. 19:712-722.

3. Windler, E., Y. Chao, and R. J. Havel. 1980. Regulation of the hepatic uptake of triglyceride-rich lipoproteins in the rat. J. Biol. Chem. 255:8303-8307.

4. Fielding, C. J. 1978. Origin and properties of remnant lipoproteins.
In Disturbances in lipid and lipoprotein metabolism. J. M. Dietschy, A. M. Gotto, and J. A. Ontko, editors. Bethesda, MD, American Physiological Society. 83-98.

5. Redgrave, T. G. 1970. Formation of cholesteryl ester-rich particulate lipid during metabolism of chylomicrons. J. Clin. Invest. 49:465471.

6. Mjøs, O. D., O. Faergemann, R. L. Hamilton, and R. J. Havel. 1975. Characterization of remnants produced during the metabolism of triglyceride-rich lipoproteins of blood plasma and intestinal lymph in the rat. J. Clin. Invest. 56:603-615.

7. Shirai, K., T. J. Fitzharris, M. Shinomiya, H. G. Muntz, J. A. K. Harmony, R. L. Jackson, and D. M. Quinn. 1983. Lipoprotein lipasecatalyzed hydrolysis of guinea pig very low density lipoproteins and discoidal complexes of phospholipid and apolipoprotein: effect of apolipoprotein C-II on the catalytic mechanism. J. Lipid Res. 24:721-730.

8. Groot, P. H. E., M. C. Oerlemans, and L. M. Scheek. 1978. Triglyceridase and phospholipase $A_{1}$ activities of rat-heart lipoprotein lipase. Biochim. Biophys. Acta. 530:91-98.

9. Fielding, P. E., V. G. Shore, and C. J. Fielding. 1977. Lipoprotein lipase. Isolation and characterization of a second enzyme species from postheparin plasma. Biochemistry. 16:1896-1900.

10. Havel, R. J., C. J. Fielding, T. Olivecrona, V. G. Shore, P. E. Fielding, and T. Egelrud. 1973. Cofactor activity of protein components of human very low density lipoproteins in the hydrolysis of triglycerides by lipoprotein lipase from different sources. Biochemistry. 12:1828-1833.

11. Wang, C., D. Weiser, P. Alaupovic, and W. J. McConathy. 1982. Studies on the degradation of human very low density lipoproteins by human milk lipoprotein lipase. Arch. Biochim. Biophys. 214:26-34.

12. Grosser, J., O. Schrecker, and H. Greten. 1981. Function of hepatic triglyceride lipase in lipoprotein metabolism. J. Lipid Res. 22:437442.

13. Nicoll, A., and B. Lewis. 1980. Evaluation of the roles of lipoprotein lipase and hepatic lipase in lipoprotein metabolism: in vivo and in vitro studies in man. Eur. J. Clin. Invest. 10:487-495.

14. Chajek, T., and S. Eisenberg. 1978. Very low density lipoprotein. Metabolism of phospholipids, cholesterol, and apolipoprotein $\mathrm{C}$ in the isolated perfused rat heart. J. Clin. Invest. 61:1654-1665.

15. Windler, E., and R. J. Havel. 1985. Inhibitory effects of C apolipoproteins from rats and humans on the uptake of triglyceride-rich lipoproteins and their remnants by the perfused rat liver.

16. Windler, E. E. T., P. T. Kovanen, Y. Chao, M. S. Brown, R. J. Havel, and J. L. Goldstein. 1980. The estradiol-stimulated lipoprotein receptor of rat liver. J. Biol. Chem. 255:10464-10471.

17. Havel, R. J., H. A. Eder, and J. H. Bragdon. 1955. The distribution and chemical composition of ultracentrifugally separated lipoproteins in human serum. J. Clin. Invest. 34:1345-1353.

18. Brown, W. V., R. I. Levy, and D. S. Fredrickson. 1969. Studies of the proteins in human plasma very low density lipoproteins. J. Biol. Chem. 244:5687-5694. 
19. Fainaru, M., R. J. Havel, and K. Imaizumi. 1977. Apoprotein content of plasma lipoproteins of the rat separated by gel chromatography or ultracentrifugation. Biochem. Med. 17:347-355.

20. Pagnan, A., R. J. Havel, J. P. Kane, and L. Kotite. 1977. Characterization of human very low density lipoproteins containing two electrophoretic populations: double pre-beta lipoproteins and primary dysbetalipoproteinemia. J. Lipid Res. 18:613-622.

21. Catapano, A. L., R. L. Jackson, E. B. Gilliam, A. M. Gotto, and L. C. Smith. 1978. Quantification of apo C-II and apo C-III of human very low density lipoproteins by analytical isoelectric focusing. J. Lipid Res. 19:1047-1052.

22. Stoffel, W., W. Därr, and K. P. Salna. 1977. Lipid-protein interaction between human apolipoprotein A-I and defined sphingomyelin species. Hoppe-Seyler's Physiol. Chem. 358:1-11.

23. Sata, T., R. J. Havel, and A. L. Jones. 1972. Characterization of subfractions of triglyceride-rich lipoproteins separated by gel chromatography from blood plasma of normolipemic and hyperlipemic humans. J. Lipid Res. 13:757-767.

24. Wahlefeld, A. W. 1974. Triglycerides determination after enzymatic hydrolysis. In Methods of Enzymatic Analysis. H. U. Bergmeyer, editor. Academic Press, New York. 1831-1833.

25. Stähler, F., W. Gruber, K. Stinshoff, and P. Röschlau. 1977. Eine praxisgerechte enzymatische Cholesterin-Bestimmung. Med. Labor. 30: 29-37.

26. Duncombe, W. G. 1964. The colorimetric micro-determination of nonesterified fatty acids in plasma. Clin. Chim. Acta. 9:122-125.

27. Broekhuyse, R. M. 1976. Spectrophotometric analysis. In Biochemical Analysis of Membranes. A. H. Maddy, editor. 275-282, Chapman and Hall Ltd., London, 175-182.

28. Fine, J. B., and H. Sprecher. 1982. Unidimensional thin-layer chromatography of phospholipids on boric acid-impregnated plates. $J$. Lipid Res. 23:660-663.

29. Bligh, E. G., and W. J. Dyer. 1959. A rapid method of total lipid extraction and purification. Can. J. Biochem. Physiol. 37:911-917.

30. Broekhuyse, R. M. 1976. Mammalian phospholipids. In: Biochemical analysis of membranes. A. H. Maddy, editor. Chapman and Hall Ltd., London, 271-272.

31. Shipley, G. G., L. S. Avecilla, and D. M. Small. 1974. Phase behavior and structure of aqueous dispersions of sphingomyelin. J. Lipid Res. 15:124-131.
32. Nilsson-Ehle, P., A. S. Garfinkel, and M. C. Schotz. 1980. Lipolytic enzymes and plasma lipoprotein metabolism. Annu. Rev. Biochem. 49: 667-693.

33. Fielding, C. J. 1981. Monoglyceride hydrolase activities of rat plasma and platelets. J. Biol. Chem. 256:876-881.

34. Bengtsson, G., and T. Olivecrona. 1979. Apolipoprotein CII enhances hydrolysis of monoglycerides by lipoprotein lipase, but the effect is abolished by fatty acids. Fed. Eur. Biochem. Soc. Letters 106:345348.

35. Eisenberg, S., and D. Schurr. 1976. Phospholipid removal during degradation of rat plasma very low density lipoprotein in vitro. J. Lipid Res. 17:578-587.

36. Bennett, C. S., and K. R. Norum. 1977. The lecithin-cholesterol acyl transferase activity of rat intestinal lymph. J. Lipid Res. 18:293300.

37. Glomset, J. A. 1968. The plasma lecithin: cholesterol acyltransferase reaction. J. Lipid Res. 9:155-167.

38. Jensen, G. L., B. Daggy, and A. Bensadoun. 1982. Triacylglycerol lipase, monoglycerol lipase and phospholipase activities of highly purified rat hepatic lipase. Biochim. Biophys. Acta. 710:464-470.

39. Van Tol, A., T. van Gent, and H. Jansen. 1980. Degradation of high density lipoprotein by heparin-releasable liver lipase. Biochem. Biophys. Res. Commun. 94:101-108.

40. Fielding, C. J., and P. E. Fielding. 1976. Chylomicron protein content and the rate of lipoprotein lipase activity. J. Lipid Res. 17:419423.

41. Van Echtfeld, C. J. A., B. de Kruijff, J. G. Mandersloot, and J. de Gier. 1981. Effects of lysophosphatidylcholines on phosphatidylcholine and phosphatidylcholine/cholesterol liposome systems as revealed by ${ }^{31}$ P-NMR, electron microscopy and permeability studies. Biochim. Biophys. Acta. 649:211-220.

42. Kurakata, S., S. Nojima, and K. Inoue. 1981. The interaction of lysophosphatidylcholine with protein-containing liposomes. J. Biochem. 90:657-663.

43. Tall, A. R., and Y. Lange. 1978. Interaction of cholesterol, phospholipid and apoprotein in high density lipoprotein recombinants. Biochim. Biophys. Acta. 513:185-197.

44. Krebs, K. E., M. C. Phillips, and C. E. Sparks. 1983. A comparison of the surface activities of rat plasma apolipoproteins C-II, C-III-0, CIII-3. Biochim. Biophys. Acta. 751:470-473. 